\title{
2 Definitions
}

These are interesting times for architecture. As existing paradigms are being eroded by external factors - be it the economic crisis or the impressive rise of mobile media - the profession seems wandering in search of a solid ground from which to rethink itself and its production. (Botazzi, 2012)

\subsection{Overview}

My research brings together the humanities and sciences whose intellectual systems are culturally distinct (Snow, 1959). ${ }^{2}$ Early definition of the various terms of reference is therefore required to familiarize readers with the broad range of subjects addressed in my work and to establish their critical context.

\subsection{Aim of Research}

Practical steps are established to enable a transition from industrial to ecological architectural practices. Using the parallel processing powers of the material world, a Nature-based production platform is informed, which evades traditional binary divisions that characterize modern architecture, such as Nature/machine, humanism/ environmentalism and matter/information. In dissolving these divisions that influence design decisions, I aim to increase the connectivity of architectural substrates and enable designers to explore new ways of thinking and making. In establishing the philosophical and cultural context for involving material properties in design solutions, I have drawn on Bennett's notion of vibrant matter (Bennett, 2010), which invites us to recognize that we share a common ontology with matter through stardust (Science Daily, 1999; Sagan, 2007), which is intrinsically lively. The fabric of our existence can therefore respond directly to spatial programs, codesign events and ultimately exert collective effects through a new technological platform based on assemblages. The properties of this platform are experimentally demonstrated using chemistry at nonequilibrium states and in different contexts, which are further developed and critiqued in project work. Research findings are used to develop a manifesto that establishes a series of principles for the practice of vibrant architecture. The conceptual and practical transitions in my research demonstrate how matter may:

2 The first popular airing of the growing 20th century rift between the humanities and science is usually attributed to C.P. Snow's 1959 Rede lecture 'The Two Cultures and the Scientific Revolution' (Snow, 1959), which proposed that the cultural differences between the arts and sciences presented a 'gulf of mutual incomprehension' that could not be reconciled. 
- Be lively

- Perform computational tasks when specific infrastructural and environmental conditions are met

- Provide self-supporting infrastructures

- Become a technology, or an architectural production platform

The themes that run through my research have been derived in a particular way and are influenced by contingent thoughts from a range of disciplines. It is therefore essential to outline the terminology that informs these ideas so that multidisciplinary influences may converge to clearly invoke specific sets of concepts from the outset and bring clarity to the proposal.

\subsection{Process Philosophy}

Although my research spans disciplines, it is united through a common set of ideas, which I refer to as 'process philosophy' (Seibt, 2012). While classical western philosophy engages with a world whose matter is effectively static where movement and process are secondary or derivative, process philosophy is concerned with the idea of 'becoming' as a primary quality of experience both for humans and the material world. Process philosophers share a set of principles that describe reality as a combination of physical, organic, social and cognitive processes, which are entangled across many levels of organization (see Fig. 2.1). Yet, within this broad framework, debates vary on how a world forged by process is construed. Examples of process philosophers include Heraclitus, Gottfried Wilhelm Leibniz, Georg Hegel, Friedrich Nietzsche, Martin Heidegger, Jacques Derrida, Alfred North Whitehead, Henri Bergson, William James and John Dewey, although this list is not exhaustive (Seibt, 2012).

\subsection{Complexity}

While the language and metaphysics of process philosophy provide the semantics that inform the design principles that I apply in my research, complexity is the science and engineering framework through which these ideas may be experimentally tested and constructed. Although complexity is a relatively new science, it is a very old idea and its principles have been explored and expressed across disciplines throughout the ages, in many ways, to deal with notions of an ever-changing reality. Works could include, for example, William Blake's notion of evanescence, the poetry and prose of the Romantics, ${ }^{4}$ Henri Lefebvre's Rhythmanalysis (Lefebvre, 2004), Jan Christiaan Smuts' idea of 'holism' (Smuts, 1998), Norbert Wiener's 'cybernetics' (Wiener, 1948; 


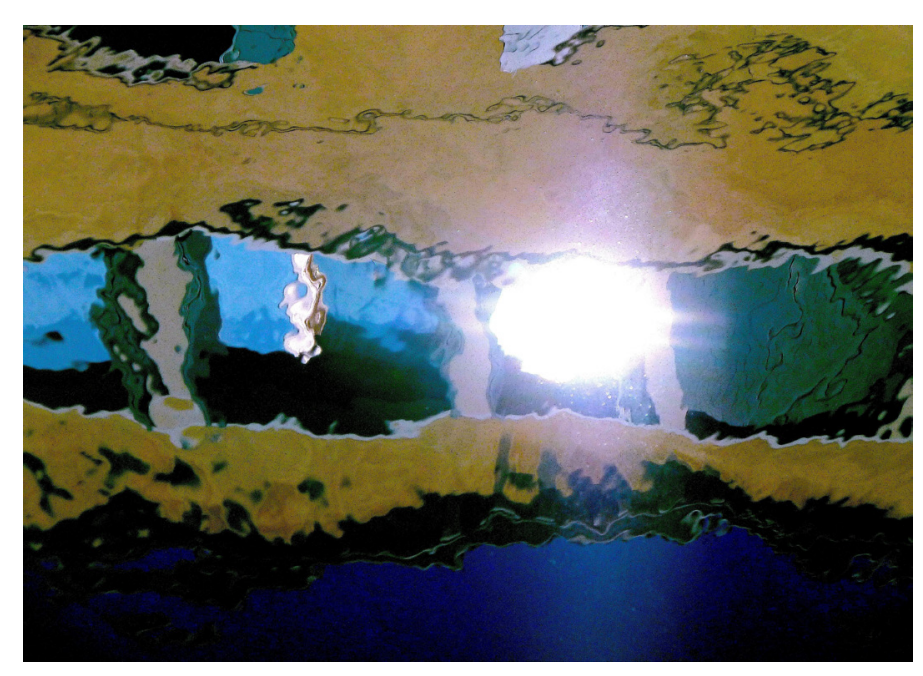

Figure 2.1: Dynamic interactions between non-object systems such as sunlight and water movement are best conveyed in terms of their processes and captured for a moment here on the surface of the Venetian lagoon. Photograph, Rachel Armstrong, August 2012.

Wiener, 1998), James Lovelock’s Gaia Theory (Lovelock, 1979), Ilya Prigogine’s 'dissipative' structures (Prigogine, 1997, p.27), Jane Bennett’s notion of vibrant matter (Bennett, 2010), Giles Deleuze and Felix Guattari's engagement with 'agentised' matter (Deleuze and Guattari, 1979), the mathematics of chaos (Gleick, 2008) and the science of non-linear systems (Schuster, 2007). In short, these many definitions and explorations denote an intellectual field that spans disciplines and, therefore, engages with a variety of methods and perspectives for working with complexity (Armstrong, 2013b).

Complexity was scientifically formalized by Ludwig von Bertalanffy, who proposed 'general systems theory' as a theoretical framework (Von Bertalanffy, 1950). This was further developed in collaboration with Ross Ashby in the emerging field of cybernetics (Ashby, 1947; Ashby, 1956) and enabled researchers across many fields to apply its principles. For example, Gregory Bateson linked together ideas in a new multidisciplinary research field (Bateson, 1972). The rise of computers enabled a graphical display of the networks and flows that underpin its organizational principles. Today, complexity is most commonly represented by endlessly branching graphics that appear like fractal trees on computer screens. Yet complexity is not an abstraction. It can be deduced from the relationships inherent in many kinds of everyday systems, which may be as diverse as the metabolism of cells (Warr, 2013), air-traffic flight patterns (National Aeronautics and Space Administration, not dated) or the movement of people around cities (Portugali, 2000). Complexity is more than speculative connections between things but encompasses embodied relationships. Theoretical physicist Albert-László Barabási characterized the behaviour of complex 
systems as being surprisingly stable, conservative, robust and resilient (Liu, Slotine and Barabási, 2011). Yet they also have the capacity to be ceaselessly creative and unpredictable. Indeed, the science of complexity is still an emerging ${ }^{3}$ discipline, so its governing principles and applications are still in development (Armstrong, 2013b).

Such perspectives are not simply intellectual fashions; they are responses to infrastructural changes in the way we live. We find ourselves at the event horizon of a generation of globally connected, digital natives whose day-to-day understanding of reality is complex, strange, disobedient and full of paradoxes. This is much more in keeping with the turbulent perspectives of process philosophy than the ordered, bounded hierarchies of the classical world and provides a way of imagining the world anew. Simultaneously, we also live at a time of quantum entanglement where it is possible for something to be in two places at once, or where we may inhabit different characters without confusion. In cyberspace, contradictions seamlessly coexist and are extensions of our natural selves - and although it does not matter if you are a dog, a tin man, or a chatbot - it does matter how well we are connected. Yet the significance of complexity has only burst into the public domain with the rise of modern computing, which enables us to describe, diagram and imagine how this reality may be constructed. With advances in processing power and speed, it has been possible to observe recognizable structures, such as veined mushroom clouds of connections that explode upwards to the megascale and downwards to the nanoscale. My research aims to explore some of these characteristics as functions - not of virtuality but through material empowerment. From an experimental perspective, complexity provides the practical frameworks that link the material realm through chemistry and architectural design, in ways that do not need instruction by external agencies - yet they may be shaped and coerced into new configurations to provide an alternative practice of 'making'.

Terms derived from process philosophy that describe the new possibilities afforded by complexity are key to designing within it. Of particular relevance to my research are the units of reality. In classical western philosophy these units are objects, the process-led equivalents being 'actants'. The operational unit of classical western philosophy is 'machine' and the process-led equivalent is 'assemblage'. These concepts are key to developing spatial programs and architectural design tactics that are not only imagined, but also designed and implemented (see Fig. 2.2).

3 Emergence is a term that proposes an alternative roadmap of organization between a mechanistic view of the world and a vitalistic one. It originates from John Stuart Mill's work in the mid 19th century that sought to describe the nature of vital substances as being composed of inanimate materials (O’Connor and Wong, 2013). 


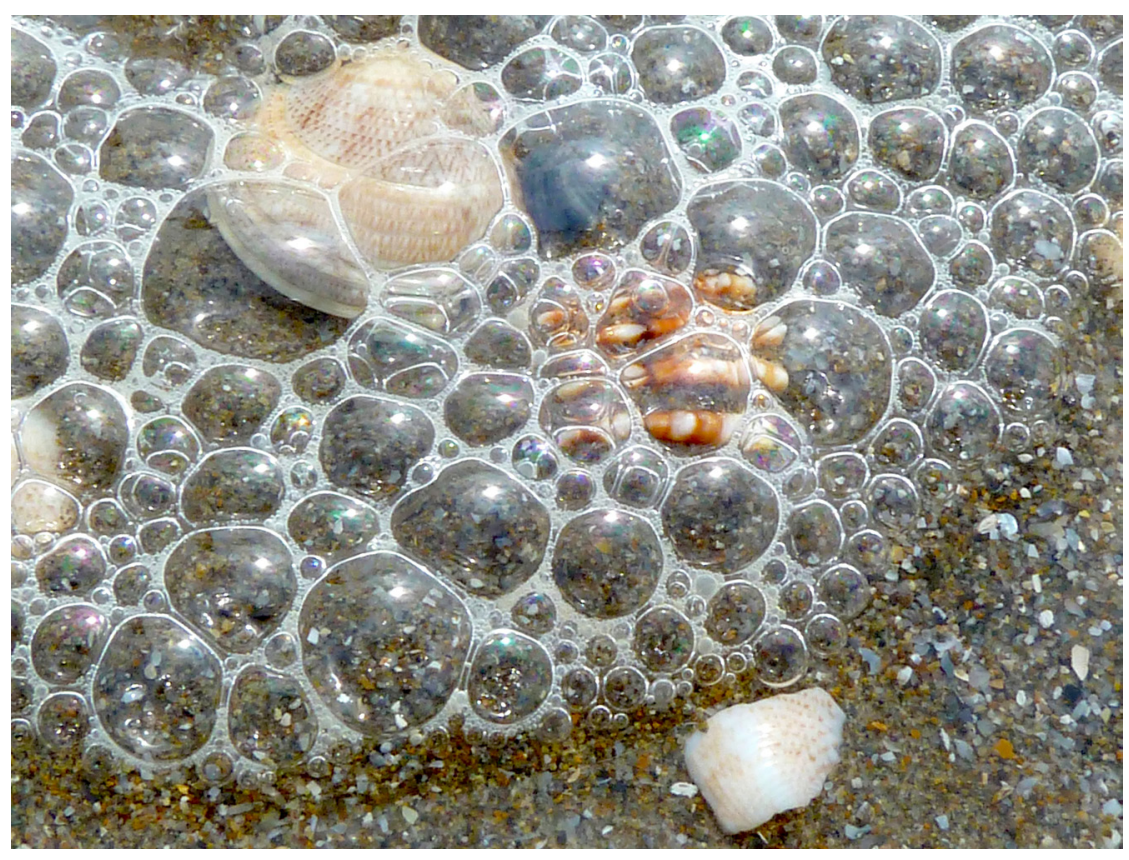

Figure 2.2: Complex interactions need not be abstracted from their environment as in this film of bubbles on the sandy shore of the Lido in Venice. Photograph, Rachel Armstrong, August 2012.

\subsection{Actant}

Actant is a literary term that is used to describe an agent that denotes the locus of action within actor network theory (ANT). ${ }^{4}$ Actants are nouns that operate as verbs and exert their diverse effects through collaboration and emergence (Latour, 1996). They may arise from a diverse assemblage of bodies including structural traits, corporate bodies, individuals or loose aggregates of individuals. Yet, none of these configurations are regarded as being more or less realist, concrete, abstract or artificial than the others in their vicinity (Latour, 2005, p.54). Bennett uses the term to denote the empowerment of matter, which renders obsolete the notion of passive objects. Actants increase their force by forming assemblages with other actants, so that non-human actors can exert autonomous forces that shape events (Bennett, 2010, p.vii). For example, power grids (Bennett, 2005) and garbage possess the capacity

4 Latour comments that actor network theory is 'a name that is so awkward, so confusing, so meaningless that it deserves to be kept ... which is ... perfectly fit for a blind, myopic, workaholic, trailsniffing and collective traveler. An ant writing for other ants, this fits my project very well!' (Latour, 2005, p.9). 
to perform work, which is conferred by many synergistic chemical processes that transform one set of substances into another (Bennett, 2010, p.6). Latour does not constrain the idea of actant to material forms (Latour, 2005, p.54) but observes that non-material entities such as ideas may produce effects. Yet, throughout my research, I use the term actant in an entirely material context, whose causal chains of action may be described through the laws of classical physics and as quantum phenomena. In this sense, actants may be regarded as embodied agents of potentiality rather than determined states of matter, such as objects. Actants may coherently exist and behave within both complex and classical scientific frameworks and, therefore, concurrently and coherently act as objects and systems. The existential paradox of matter was first observed and experimentally tested for the electromagnetic spectrum, in which light was demonstrated to simultaneously behave as a stream of particles and also as waves (Moskowitz, 2012). My research also proposes that, in keeping with the Correspondence Principle (Nielsen, 1976, pp.241-282), the paradoxical nature of the electromagnetic spectrum may be mirrored at the human and architectural scales, where linking the quantum world to the macroscale, through vibrant matter, could potentially offer new opportunities for architectural design practice. By achieving the status of a real material phenomenon, actants potentially offer an important conceptual and practical bridge between the subatomic and macroscopic world, where they may coherently operate in the worlds of objects as well as participating in the flows of material that characterize systems (see Fig. 2.3).

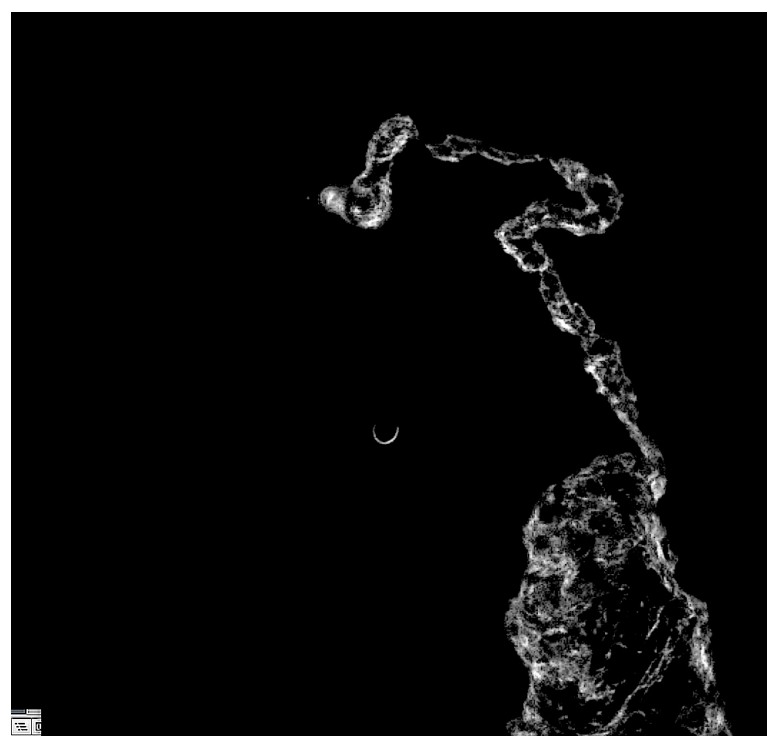

Figure 2.3: Actants are far from equilibrium systems that have the potential to form molecular bonds with other bodies. Here, a dynamic droplet is depositing a complex 'osmotic crystal skin' in the environment, while moving in a strikingly lifelike manner. Micrograph, magnification 4×, Rachel Armstrong, November 2009. 


\subsection{Assemblage}

The concept of assemblage is from the French word agencement, used by Gilles Deleuze and Felix Guattari to denote specific connections between groupings of actants ${ }^{5}$ that form loose, reversible associations with each other. Their combined actions produce complex agents composed of many different, interacting bodies such as soil. Bennett notes, 'Bodies enhance their power in or as a heterogeneous assemblage ... Assemblages are ad hoc groupings of diverse elements, of vibrant materials of all sorts' (Bennett, 2010, p.23). Through their interactions, assemblages behave according to the laws of complexity and may give rise to new meanings or effects in creative and often unpredictable ways (Deleuze and Guattari, 1986, p.22) (see Fig. 2.4). Since changing their internal, or external, conditions may alter the behaviour and effects of assemblages, they may also be considered as a form of technology that can be shaped by morphological computing techniques and may be considered as a Nature-based production platform. For example, the Dutch generative artists Erwin Driessens and Maria Verstappen use scientific processes to evolve images and sculptures. Driessens and Verstappen explore chemical systems such as wax and sand, which undergo transformations caused by physical changes in the local environment controlled by heat or vibration (Whitelaw, 2003; Siggraph, not dated) that take these substances away from an equilibrium state. The agency that is giving rise to these transformations is an assemblage, since it does not reside in any one component of their installation, as the potency of process is dependent on the artificial environments set up by the artists and also resides within the chemistry of the transmuting material itself.

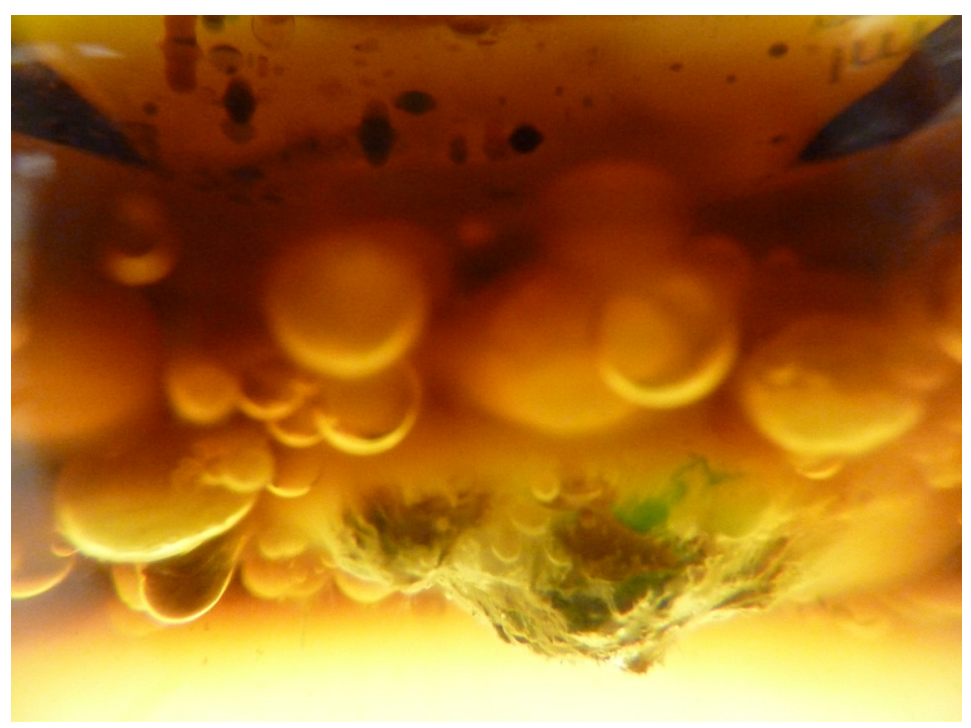

Figure 2.4: Modified Bütschli droplets form assemblages that interact and transform one another to produce novel events such as crystalline structures. Photograph, Rachel Armstrong, February 2010.

5 Actant, agent and body are considered synonyms and used interchangeably. 


\subsection{Nature}

Nature is really more of a dialectical formation where we endlessly remake Nature, and Nature remakes us. (Gissen, 2011)

My research suggests that architectural design practice may explore a more Naturebased form of making, by proposing that matter can spontaneously act through a new technological platform enabled by assemblage formation (see Fig. 2.5). In this context, Nature can be thought of as being composed of terrestrial, heterogeneous (material) ${ }^{6}$ agents that are not commanded by a single providence, or (meta)agency, but are free to differentiate (Latour, 2013). Indeed, my research proposes that not only is Nature an agency that can be materially moulded by physical interventions such as gardening, but may be further shaped according to cultural and technological milieux (Van Mensvoort and Grievink, 2012).

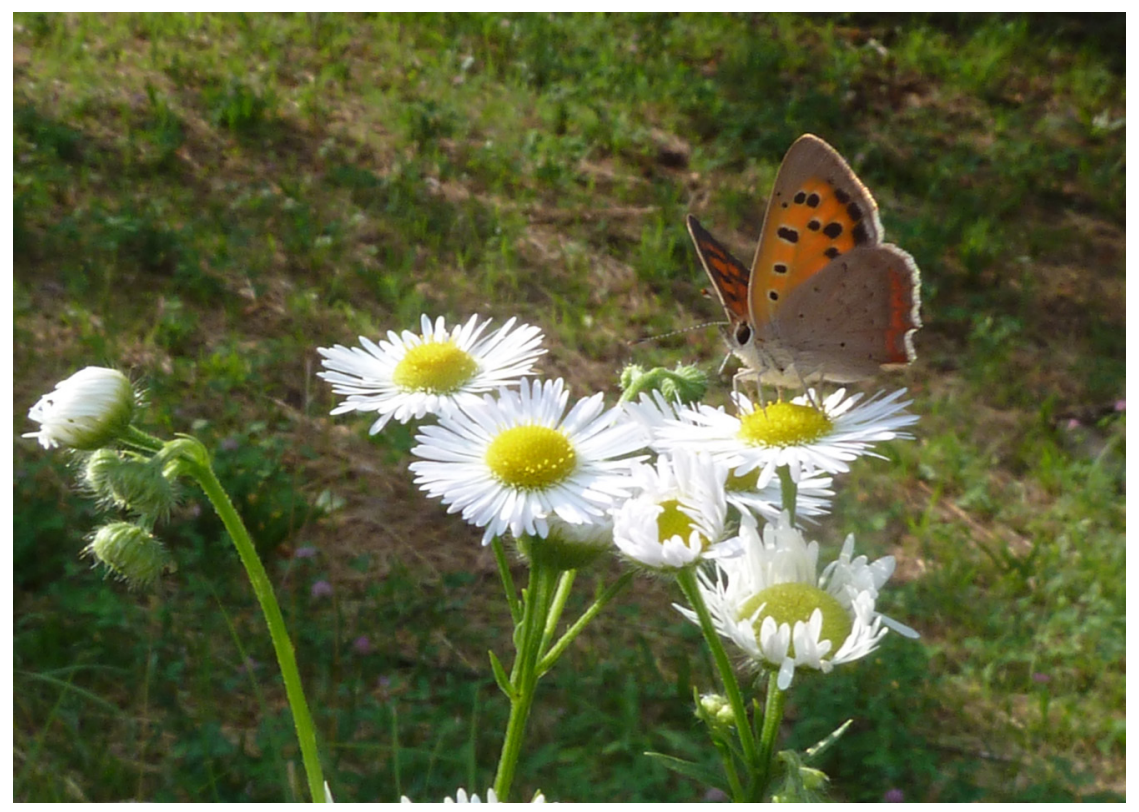

Figure 2.5: Nature is shaped by assemblage formations that shape the natural world, such as resource exchanges between flowers and butterflies. Photograph, Rachel Armstrong, July 2013.

6 In his Gifford lecture series, held at the University of Edinburgh, 2013, Latour specifies these active material agents as 'chemical instabilities', or metabolisms. The role of these agents is to act so they prevent material systems from 'rushing towards equilibrium' (Latour, 2013). 
Latour proposes that western cultures have 'prematurely unified' the idea of Nature (Latour, 2013), leaving us conditioned by a 'closed' set of relationships. He observes that James Lovelock and Lynn Margulis's notion of Gaia serves as a secular model of Nature that creates the condition by which our living world may possess its own agency and, therefore, effectively constitutes a living body (Lovelock, 1979). Indeed, Latour proposes that, based on the potentially infinite possibilities that may influence our experience of Nature, our planet is a discontinuous multiverse ${ }^{7}$ from which we may begin to 'compose our cosmos' (Latour, 2013). Whitehead notes the importance of humans in shaping Nature and proposes that without human experience and subjectivity the natural world is little more than 'a dull affair, soundless, scentless, colourless; merely the hurrying of material, endlessly, meaninglessly' (Whitehead, 1970, p.54). Since humans and all of these factors that influence our encounters with reality are constantly changing, Nature invariably refers to different models of experience. It therefore requires a specific definition, which is referred to as 'Millennial Nature'. Like Morton, I capitalize the word to highlight its 'unnatural' qualities (Morton, 2012, p.3) that may be described using the laws of complexity and metaphysics of process philosophy.

\subsection{Millennial Nature}

In my research, the term Nature refers to a very specific set of cultural, technological and ecological conditions (Van Mensvoort and Grievink, 2012) that pertain to 21st century challenges. This 'Millennial Nature' is not the bucolic, untouched wilderness that the Romantics swooned over but a version of Nature that has been deconstructed and stripped of its aestheticisms to reveal its raw, relentlessly material character (Morton, 2007). Millennial Nature is not an Enlightenment 'standing reserve' (Heidegger, 1993) that awaits mechanical instruction, nor is it an anti-modern, vengeful force that seeks to usurp humankind (Koolhaas, not dated). Rather, it is forged through the horizontal coupling $^{8}$ of different species of lively material agents, which negotiate many difficult relationships through the production of assemblages. Yet these are not utopian fabrics devoid of struggle or contradiction. They are wilful and must be managed not repressed - so their constituents may respond favourably to human requirements. Millennial Nature is not anti-human but implies a new relationship with humanity that demands to be engaged and nurtured, not tamed (see Fig. 2.6). It embraces many

7 Latour's term of reference for a non-prematurely-unified notion of the cosmos is 'multiverse', or 'pluriverse' (Latour, 2013).

8 By 'horizontal coupling' I mean the propensity for all matter at all scales to form relationships through subatomic interactions and the forging of molecular bonds so that there is effectively no top-down, or bottom-up hierarchical ordering but continual negotiation between assemblages that occur at all scales. 
different substrates such as inorganic agents (Woods, 2012a), biological systems, weather, geological forces, soils, oceans, atmosphere, gravity, light, star systems, black holes and humans. Indeed, Millennial Nature is the fabric of reality, at all scales, which can only be perceived in relationship to human activity - but which acts entirely independently of us. Millennial Nature is not just an alternative organizing system but possesses technological characteristics that construe an alternative production platform to machines for the synthesis of new systems and fabrics.

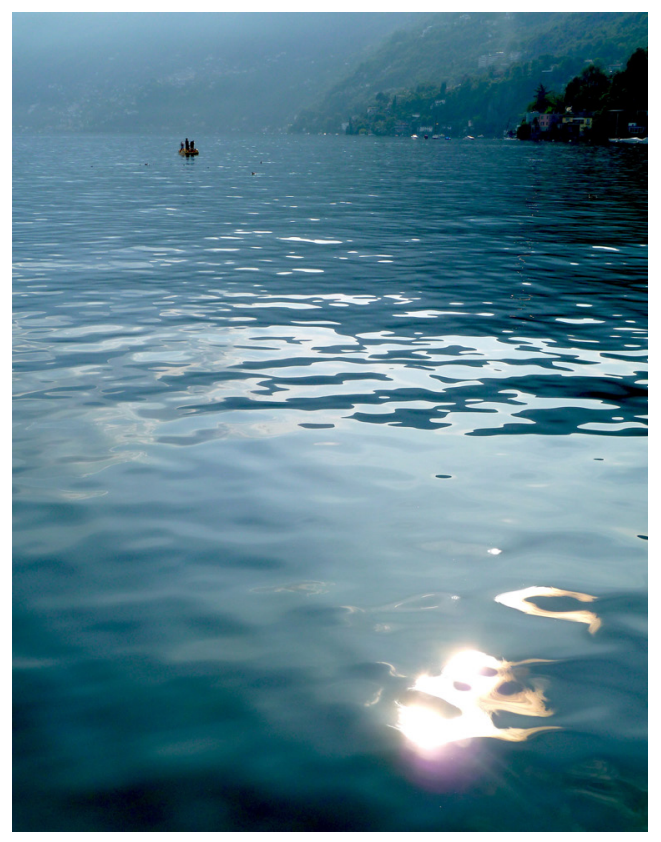

Figure 2.6: A dinghy afloat in Lake Maggiore, Ascona, Switzerland encapsulates the character of Millennial Nature as a powerful set of forces that are neither 'for' or 'against' humans. Photograph, Rachel Armstrong, July 2013.

\subsection{Post-natural}

... the new biotechnological paradigm in architecture, which marries mixed (for old and new) technologies and biology, creating the means by which as logic of life can be mapped and engaged in architectural design processes ... (Frichot, 2011)

If machines are the embodiment of an object-centred culture and Nature is a cultural expression of processes, then the post-natural is where these worldviews converge 
through new material syntheses and transformations. The post-natural indulges the complex interplay between cultures, Nature, ecology and biotechnology, which results in the seamless integration of artificially designed and engineered agents into the environment, such as genetically modified organisms or cybernetic systems (Gilster, 2014).

Post-natural landscapes are cultural readings of the environment where human and non-human agents are materially integrated through fluctuating chemical exchanges and are invisible to inhabitants, who consider these fabrics as everyday experiences, such as the 'new normal' (Luebkeman, 2012), or 'Next Nature' (Van Mensvoort and Grievink, 2012.). In the same way that the post-digital age has witnessed a generation of children that poke at paper expecting it to jump into interaction with them (YouTube, 2011), post-natural natives expect their environments to be lively, not inert, and respond to them at the human scale. The convergent terrains harbour a spectrum of conditions and experiences that are as varied as the configuration of life itself. Examples of emerging post-natural landscapes include the transformation of native biomes by industrial toxins (Paul, 2011) and more strategic proposals to entangle artificial and natural systems (YouTube, 2009; Meier, 2013; Sterling, 2013) (see Fig. 2.7).

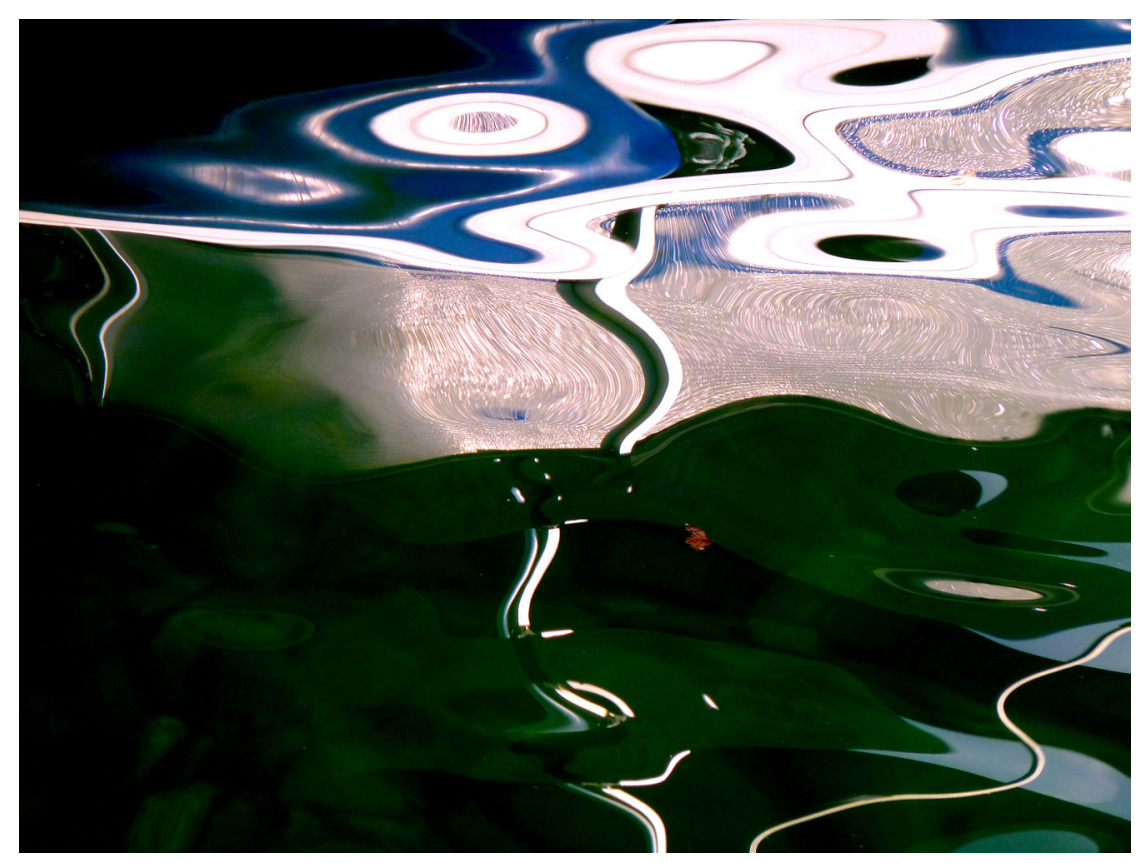

Figure 2.7: Reflections of a boat hull in Lake Maggiore, Ascona, Switzerland produce maps of connections from which post-natural fabrics may be formed. Photograph, Rachel Armstrong, July 2013. 


\subsection{Ecology}

The term 'ecology' is a scientific view of Nature lacking subjective interpretation (Whitehead, 1970, p.54). It has been widely adopted as a way of talking about relationships between actants that exist in the natural world that have not been culturally aestheticized or defined by their materiality. Yet the idea of ecology itself has evolved since Ernst Haeckel first coined the term 'Oecologie' in 1886 (Wimberley, 2009, p.6; Haeckel, 1866). His organism-centred perspective was inspired by Charles Darwin's theory of modification by descent (Darwin, 1999) and was concerned with the nature of the relationships between organisms and their environment, which influenced the development of new species. By the middle of the 20th century, Herbert Andrewartha and Charles Birch recognized that a complex web of non-biotic factors influenced the abundance and distribution of animals (Andrewartha and Birch, 1984). However, Howard and Eugene Odum emphasized the importance of the mineral world in shaping evolutionary events and gave it equal status to the animal world. They championed Arthur Tansley's ecosystem view of the world (Willis, 1997), which was centred on how creatures thrive through the continual exchange of vital materials (Stuart, Matson and Mooney, 2002, pp.7-11). In a contemporary ecological context, these networks not only relate to the development of biotic communities over time but may also refer to the flow of matter and energy through elemental cycles such as carbon, nitrogen, phosphorus and water.

As the scientific study of complex systems has developed (Capra, 1996), its material embodiment has become equated with ecology and is practised through a range of multidisciplinary collaborations between scientific disciplines such as biology, physics, chemistry, permaculture, soil studies, bacteriology, atmospheric science, geology, oceanography and geography and non-scientific fields such as ethics, panarchy, economics, art, humanities, politics, design, philosophy, law and resource management. A broad range of commercial practitioners also currently qualifies the environmentally beneficial nature of their services using the term ecology. For example, the construction engineering firm WSP Group defines 'urban' ecology as 'bringing the power of ecology to buildings ... to create solutions that integrate Life, Energy, Water, Nutrients and Future potential into interlinked cycles' (WSP, not dated). An ecological approach to architecture, therefore, not only deals with the scientific ideas embodied in complexity but also raises questions about the production of space (Lefebvre, 1991). Therefore, ecology inevitably deals with the cultural ideas that shape our relationship with the natural world but through the lens of science.

Accordingly, architects have embraced a diverse set of terms to refer to specific aspects of these relationships, such as sustainable (Turrent, 2008), 'green' design (Edwards, 2010), eco-architecture (McDonough and Braungart, 2002), bioclimactic architecture (Dahl, 2009), biomimicry (Beynus, 1997), zero (carbon) footprint buildings (Godfrey-Cook, 2011), passive houses (Cotterby and Dadeby, 2012) and architectures 
made from recycled materials (Laylin, 2012). In the context of my research, ecology refers to a scientific view of a multidisciplinary and practical engagement with complex embodied systems. These relationships shape and build functional networks that are culturally and aesthetically entangled with diverse communities of actors (Armstrong, 2012b; Armstrong, 2013b). An '(eco)systems' view of reality challenges the conceptual frameworks that depict the natural world as composed of discrete objects, bodies or forces such as biology, geology, climate and the oceans (see Fig. 2.8) and links these heterogeneous actants through internal metabolic processes and external, global material flows.

Indeed, Ecologist Fern Wickson wonders whether - if humans are intertwined in a complex web of biological systems and therefore cannot be included within a definition of Nature, where 'an atom bomb becomes as "natural" as an anthill' - an alternative understanding of Nature is needed (Wickson, 2008). However, changing the definition of Nature is not the solution to Wickson's conundrum - the paradigm in which it is imagined requires adjusting. The classical scientific method, based on Cartesian thinking - which Kauffman calls the 'Galilean spell' (Kauffman, 2008, pp.129-149) - is actually responsible for the paradox Wickson seeks to contest. The Galilean spell is founded on irreducible binaries such as mind/body, human/machine and Nature/artifice, so if the problem of human connectedness to the natural world is to be resolved, then the scientific framework used to describe it needs to change.

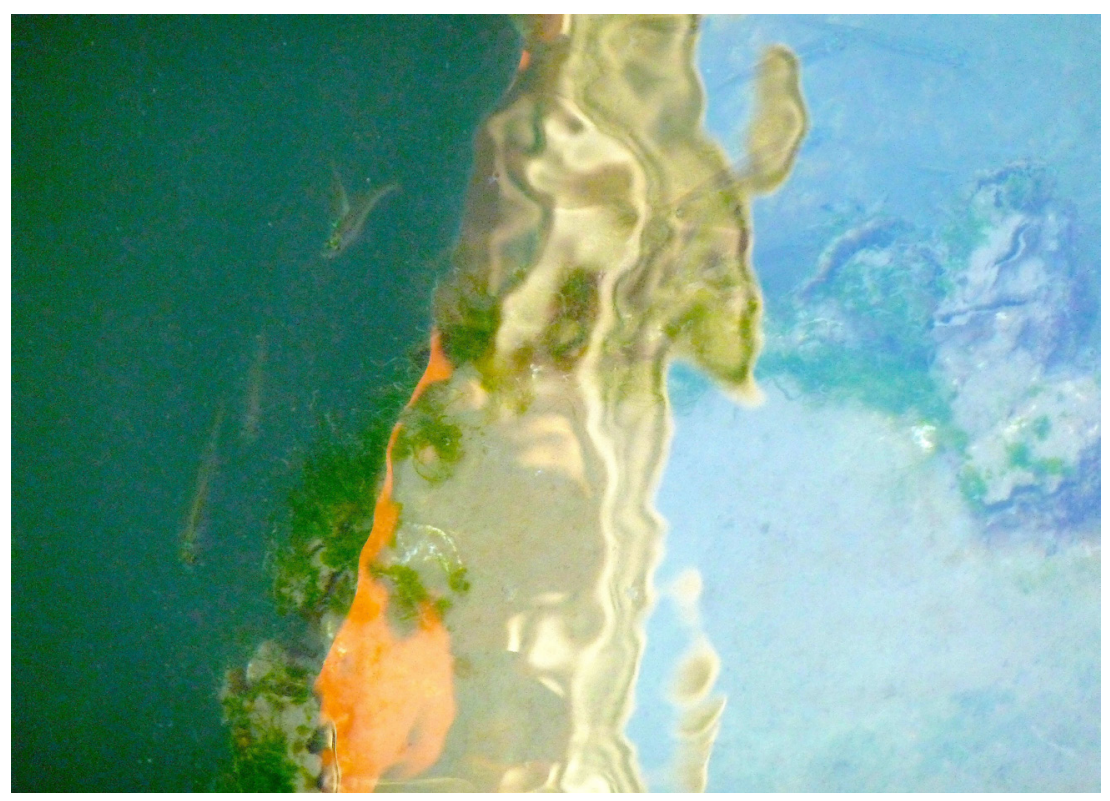

Figure 2.8: Reflections within a Venetian canal encapsulate complex, ecological interactions between humans and the natural world. Photograph, Rachel Armstrong, August 2012. 
Robert Rosen observed that when physics is used to describe biology, a generalization occurs that distorts reality (Rosen, 1996, pp.199-214). He proposed that formal definitions of 'life' set limits that are caused by an excess of 'rigour' in mathematics, and 'objectivity' or 'context independence' in science (Rosen, 1999, p.2). Similarly, Turing noted in his essay on morphogenesis that mathematical abstraction could not capture the richness of the natural world (Turing, 1952), since life is a complex system that is governed by a variety of unique processes that machines simply do not possess. Living things continually respond and adapt to their environment and are made up of networks of assemblages which enable them to self-regulate and express increasing degrees of agential autonomy (Maturana and Varela, 1980). Yet Deutsch notes that reductionism is not the only form of science and proposes that scientific inquiry is not about making predictions based on observations, but serves a broader function in finding explanations (Deutsch, 1997, p.71).

This is exactly what complexity does, but rather than being based on inductivism, ${ }^{9}$ it is informed by process philosophy (Seibt, 2012). Since a complex worldview is based on concepts that relate to networks, relationship and flows that cannot be reduced into their parts, it challenges the ontological and epistemological basis on which technologies that have been championed by modern science and industry, are founded. So what does 'systems' science (Von Bertalanffy, 1950), or complexity, mean for our relationship with Nature? Are we separate from or intrinsically connected to the natural world? In a complex system, we are both, and experience reality as being formed by both processes and objects and also from subjective and objective perspectives. For example, a building may be thought of as an object but it is also a site for many processes that may have brought about its construction, enable site activities and ultimately contribute to its decay. We may also observe and measure these material changes and consider them beautiful and encourage them, or disagreeable and seek to prevent or repair them. However, our understanding of which processes are important are culturally determined and are not Platonic truths. Indeed, Bruce Sterling proposes a play on Arthur C. Clarke's dictum ${ }^{10}$ and wryly observes, 'Any sufficiently advanced technology is indistinguishable from its garbage' (Sterling, 2012). Sterling's reference to garbage suggests how we can be connected to Nature - but not in an unlimited way. Garbage-making is a subjective exercise in which we distinguish ourselves from the natural world, and our technologies, by 'editing' our material networks to reflect our cultural conditioning. We choose what is important to us by applying cultural and aesthetic, rather than material criteria, to make the appropriate selections. Turing had already grasped the importance of personal bias in dealing with complex systems

9 According to Deutsch, inductivism produces scientific theories by extrapolating the results of observations, which are justified when corroborating evidence is obtained (Deutsch, 1997, p.71).

10 Clarke's dictum from his Third Law, in the essay 'Hazards of prophesy: The failure of imagination' states 'any sufficiently advanced civilization is indistinguishable from its technology' (Clarke, 1973, p.21). 
and devised the 'imitation game' to address the conundrum of intelligence, which evaded an easy empirical solution. This is now more popularly known as the 'Turing Test' and is now being used more widely to fathom complex systems and to identify 'life' (Cronin et al, 2006). Ultimately, the flow and structure of information within our ecological systems are important in establishing what technology, architecture, garbage and 'life' is - and indeed, what design is.

\subsection{Technology}

Throughout my research, I use Martin Heidegger's notion of technology, which does not restrict the term to any specific material form or instrumental process but considers how the idea of technology reveals truths about the world (Heidegger, 1993). Heidegger engages the concept of technology as a process and resists collapsing the concept into descriptions of objects and their hierarchies. Yet, Heidegger equates technology with industrial machines, which he views as being destructive in the thought processes they embody and the kind of influence this exerts on the material world. At the heart of Heidegger's quest is an ecological project where he seeks a free relationship between technology and humanity, to establish a new relationship with Nature, which is not ultimately self-destructive. Heidegger's idea of technology may be extended to nonmechanical systems, such as process-led ecological living technologies (ELT: see 2.13) that harness the properties of lifelike systems, (see Fig. 2.9). My research develops the notion that a non-object-centred view of the world allows us to conceive of more Nature-based forms of technology and design solutions that have qualitatively different environmental impacts than mechanical technologies.

\subsection{Machines}

Machines may be regarded as an expression of a human culture of objects through the design and construction of functional object hierarchies. These chains of order require centralized, hard control systems that are designed to operate the objects when they are at equilibrium - the lowest possible energy state within an environment. They also need an external energy source to tip the system away from equilibrium, so they may conduct useful work. Machines embody an atomistic worldview and are based on Cartesian principles characterized by binaries, objects, hierarchies of order and geometry (see Fig. 2.10). While we have increasingly come to equate technology with machines, or gadgets, my research makes reference to other kinds of technology, whose operational principles are more in keeping with a Nature-based form of practice. Alternative technological systems to machines may, for example, possess innate energy by existing at far from equilibrium states, engage parallel forms of 


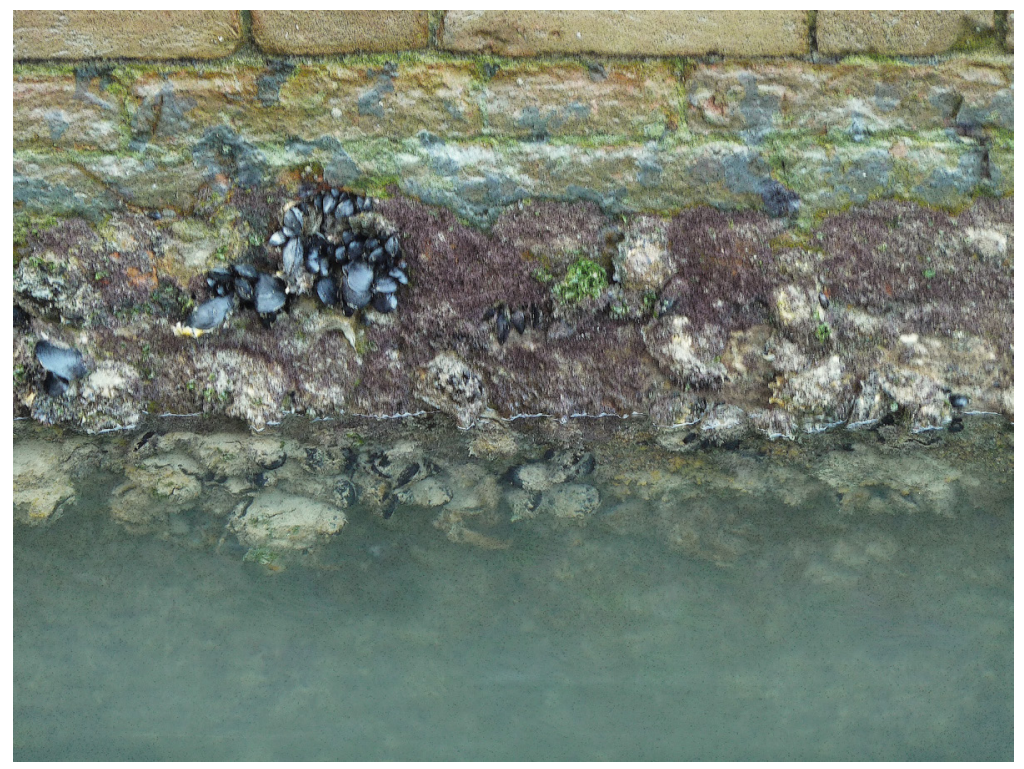

Figure 2.9: This reflection in a Venetian canal notionally suggests that buildings may be grown from an elemental recipe, rather than constructed using prefabricated components. Photograph, Rachel Armstrong, July 2013.

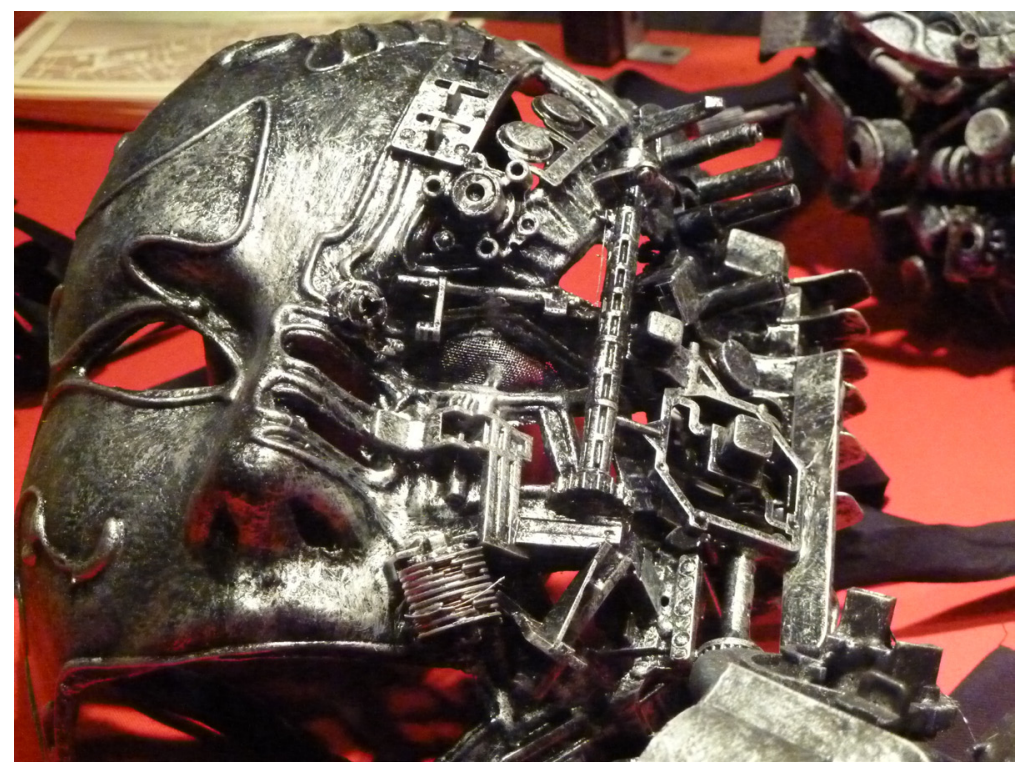

Figure 2.10: This Venetian mask design depicts the human body as a machine. Photograph, Rachel Armstrong, August 2012. 
multidimensional processing and invite soft forms of control, since their agency is distributed throughout their constituent assemblages.

\subsection{Ecological Living Technology}

Ecological living technology (ELT) is a process-led platform which is composed of non-hierarchical groupings of material assemblages that can perform useful work and whose outcomes may be shaped by altering the internal and external conditions of the system. This is different to the expectations of classical machines whose performance is controlled by designing programs that control the internal state of the machine. ELT is an amalgamation of two concepts, 'living technology' and 'ecological technology', which deal with uniquely 21st century technological imperatives, namely:

- The desire to produce more 'ecological' forms of technology with operational processes that benefit, rather than harm the environment.

- The increasing lifelike nature of technological developments.

Bütschli droplets are an example of ELT. They are programmable, chemical agents capable of growing microstructures (see Fig. 2.11). ELT also includes modified or natural biological systems, such as synthetic biology, which harness metabolic qualities to produce their lifelike outputs, like growth, repair, reproduction and locomotion. From a design perspective, ELT aims to reveal and harness new opportunities in architectural design using different species of vibrant matter as a form of technology. These produce work through the formation and destruction of chemical bonds that can be instructed by embodied computational methods.

\subsubsection{Living Technology}

'Living technology' was coined by a consortium of interdisciplinary researchers ${ }^{11}$ at the Initiative for Science, Society and Policy (ISSP) at the University of Southern Denmark, which refers to technology that is based on the core features of life (Bedau et al, 2010). Living technology has a broad definition that refers to technologies with lifelike qualities, which may be machines or organisms, and is subdivided into 'primary' and 'secondary' living technologies (Bedau, 2009).

— 'Primary’ living technologies exhibit lifelike behaviours yet do not possess any biological parts.

- 'Secondary' living technologies harness organisms to perform their tasks, such as genetically modified bacteria, or in vitro fertilization.

11 I was a member of this group (University of Southern Denmark, 2012). 


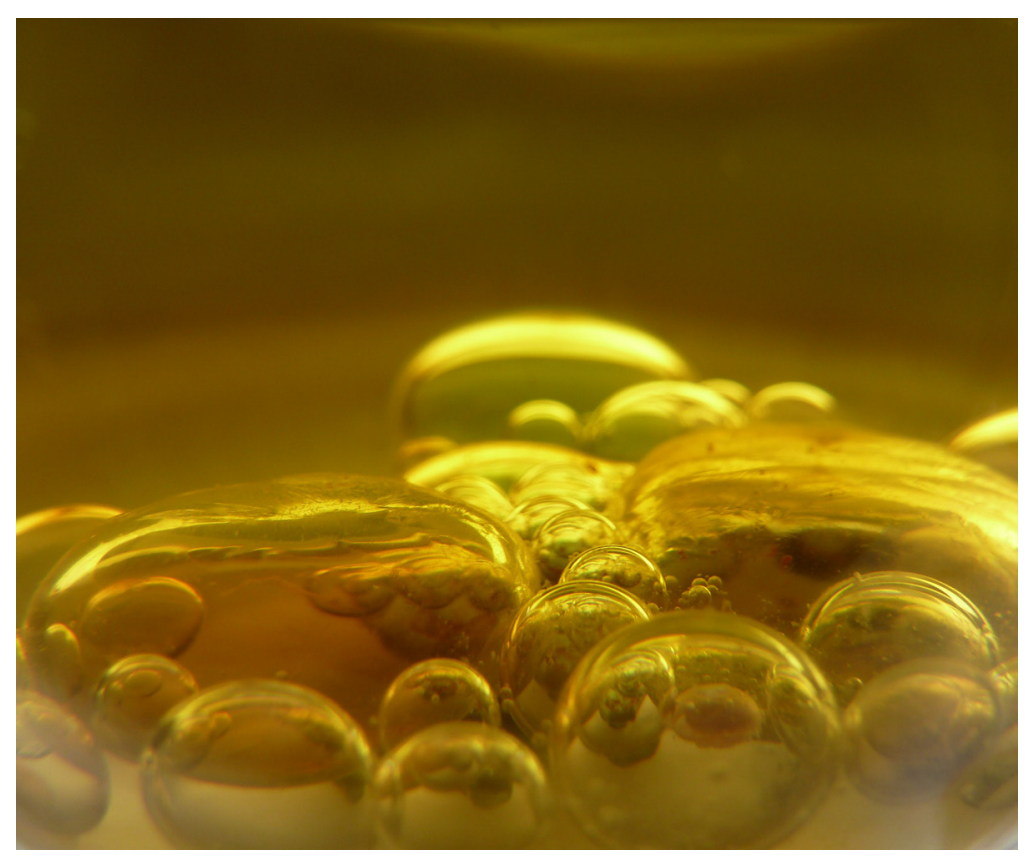

Figure 2.11: Modified Bütschli droplets process spatial chemical programs and form dark mineral deposits within the body of a droplet cluster. Photograph, Rachel Armstrong, February 2010.

Living technology is also connected with other scientific fields including artificial life (soft, hard, and wet), synthetic biology ${ }^{12}$ (top-down and bottom-up: see 2.14), and the convergence of nano- and bioinformation, and cognitive (NBIC) technologies (Bedau et al, 2010). ${ }^{13}$ However, what may or may not count as living technology is debatable. For example, a horse may be considered a living technology dedicated to transport, while a dog is a living technology bred for companionship and security. Additionally, simple tools, such as a spanner or hammer, could be considered as secondary living technologies if they are regarded as a system of work-performing assemblages, where human and instrument are reversibly coupled together to achieve a task. Living

12 Synthetic biology has been popularized as an exclusively biological form of technology but originated as an offshoot of synthetic chemistry (Leduc, 1911) and is further discussed by A.G. CairnsSmith (Cairns-Smith, 1971; Cairns-Smith, 1987; Cairns-Smith, 1990).

13 The so-called NBIC (Nano, Bio, Info, Cogno) convergence is an innovation initiative that followed an NSF (National Science Foundation) sponsored report, which has been particularly influential in precipitating a new kind of scientific approach suggesting unification of the sciences as a common goal through converging advanced technologies to provide the practical basis for the retranslation of humanity, in keeping with the pursuit of Julian Huxley's vision of transhumanism where 'the human species will be on the threshold of a new kind of existence' (Huxley, 1957, pp.13-17). 
technology also prioritizes the status of mechanical systems (primary) over that of modified, or technologized biological ones (secondary). Indeed, the all-embracing nature of the terminology led to criticism during the initial ISSP workshops (University of Southern Denmark, 2012) that the term may be applied so generally that it is almost meaningless to use it. However, from an applied design perspective, living technology conjures up different expectations of technology and conditions associated with their use (Armstrong, 2010c), which is relevant to my research ambitions in identifying more environmentally enriching technological approaches.

\subsubsection{Ecological Technology}

William Mitsch used the term 'ecological technology' in reference to systems with properties that distinguished them from conventional, industrial technologies (Mitsch, 1993). These technologies could be designed to perform particular kinds of work by choosing initial species and establishing the starting conditions of the system (see Fig. 2.12). Ecological technologies are partly created by natural forces such as molecular self-assembly, but also shape the output of the technical system by virtue of their own agency.

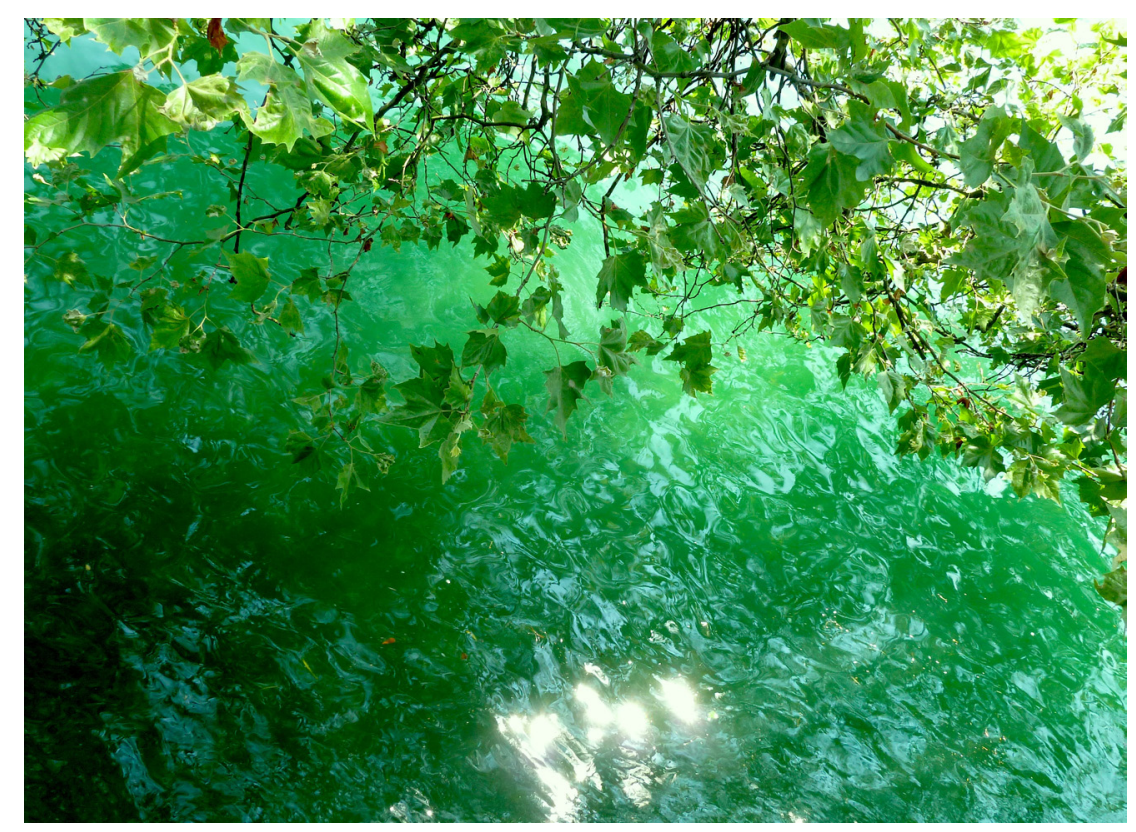

Figure 2.12: Could trees be regarded as ecological technology? A tree captures sunlight, carbon dioxide and uses water to produce outputs that may be shaped by human agencies to perform useful work (Living Root Bridges, 2009). Photograph, Rachel Armstrong, July 2013. 


\subsection{Synthetic Biology}

Synthetic biology is a relatively new scientific field that involves the rational design and engineering of living systems, which provides the tools and methods that underpin novel problem-solving tools and materials. Synthetic biology may be regarded as a specific example of ELT which provides access to the assemblage-based technology implicit in the natural world. With the rise of biotechnology, synthetic biology has become equated with genetically modified agents. Yet, the term was coined by Stephane Leduc (Leduc, 1911) and refers to the transition from chemical to biological systems (Cairns-Smith, 1971; Cairns-Smith 1987; Cairns-Smith 1990) (see Fig. 2.13).
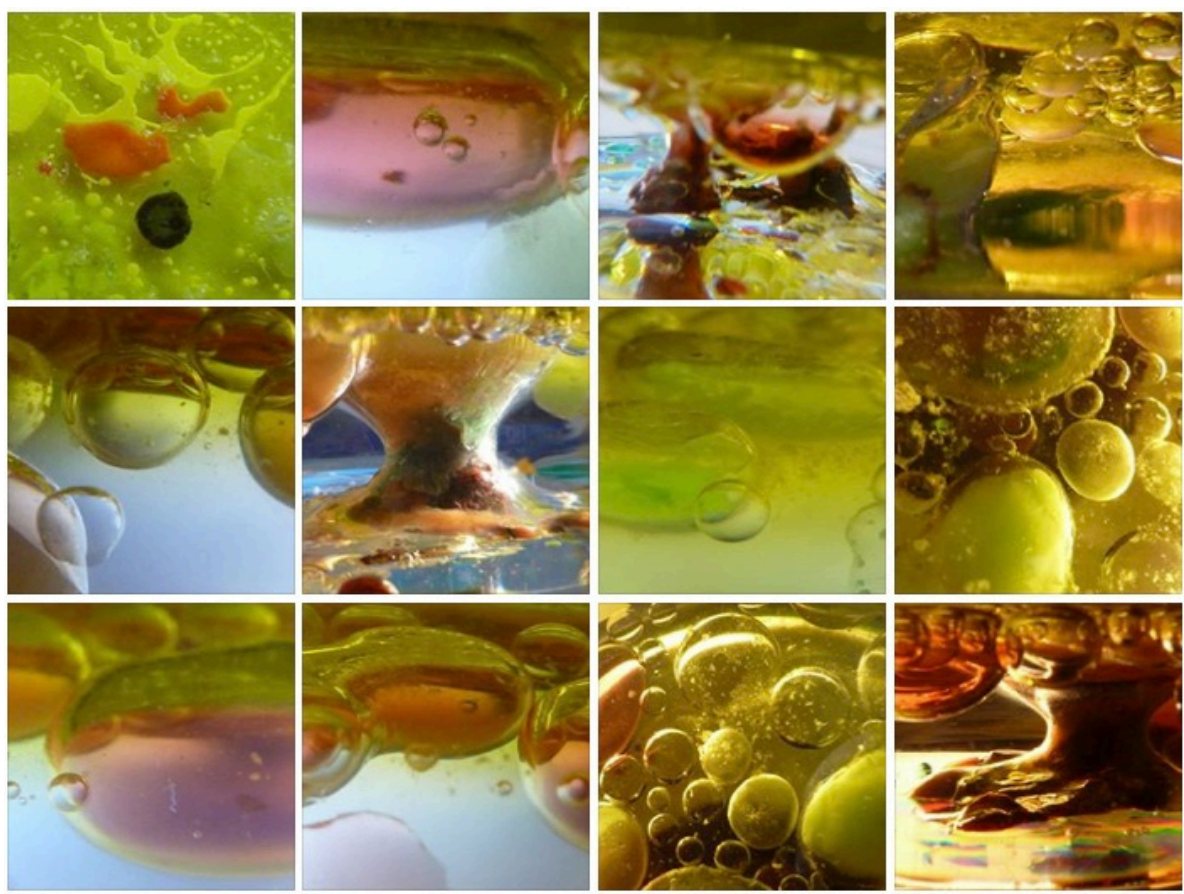

Figure 2.13: In this photograph complex chemical species are behaving in lifelike ways (Leduc, 1911). Photographs and collage, Rachel Armstrong, July 2013.

\subsection{Synthetic Ecology}

Synthetic ecology refers to the rational design and engineering of environmental networks and can be thought of as the 'systems' version of synthetic biology. 


\subsection{Protocell}

Non-biological materials may also exert lively effects. My research examines how chemical assemblages that are not technically 'alive' may be considered and applied as ELT. My experimental work explores a range of vibrant materials that take the form of a series of non-equilibrium chemistries ranging from Liesegang rings (Liesegang, 1869) to Traube cells (Traube, 1867) and dynamic droplets (Bütschli, 1892; Hanczyc et al, 2007; Toyota et al, 2009). Most of my technological research is conducted using a specific species of dynamic droplet called the Bütschli system, whose products are generally referred to as 'dynamic droplets' rather than 'protocells', which has been used in other publications. My choice of terminology in this particular instance is based on the controversial and ambiguous nature of the term protocell, which invites a broad range of definitions. Sometimes it has been used interchangeably with 'vesicle' (Szostak, Bartel and Luisi, 2001), while at other times it may indicate fully artificial chemical cells capable of replication (Rasmussen et al, 2003; Rasmussen et al, 2008). My preferred definition, however, is an etymological one, where protocells are simple chemical systems with lifelike properties that serve as models for the earliest form of natural living cells. ${ }^{14}$ I have therefore used the term dynamic droplet, or Bütschli droplet, to refer to a specific example of a broader portfolio of agents that may also be described as protocells. Since I have already written on the subject of dynamic chemistries using the term protocell (Armstrong, 2011d; Armstrong, 2012g), the term appears in the text where it references a specific piece of work, or where it is used in a popular context, such as in the speculative narratives like 'Post-Natural Venice'.

\subsection{Natural Computing}

The term 'natural computing' was inspired by Alan Turing's interest in the computational powers of Nature (Turing, 1952; Denning, 2007), which operates at the level of molecular interaction. Natural computing processes inform the behaviour of ELT and ultimately inform the networks of chemical exchange in the living world, therefore enabling a more Nature-based form of technology. The possibilities of natural computing have been further developed by David Deutsch to embrace the quantum realm. Deutsch proposes that Turing's abstract computer must be substituted by an actual, physical, universal quantum computer derived from the Church-TuringDeutsch principle, which could reveal the computational possibilities of the natural world (Deutsch, 1985; Copeland, 1997) (see Fig. 2.14).

14 Protocells are 'primordial molecular globules, situated in the environment through the laws of physics and connected through the language of chemistry' (Spiller and Armstrong, 2011). 

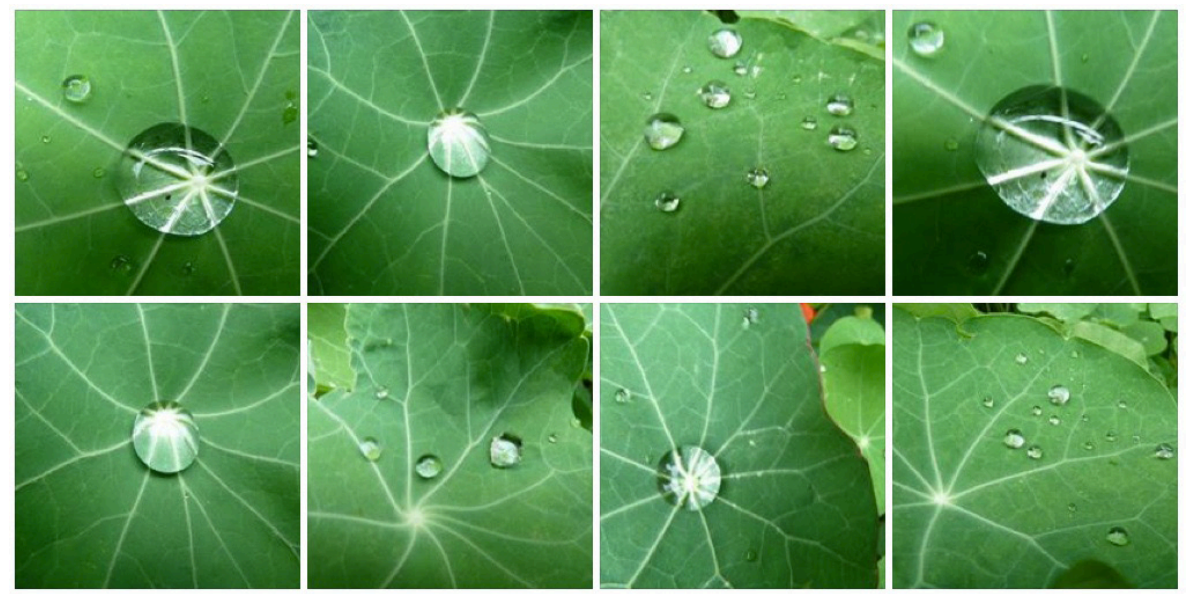

Figure 2.14: A leaf may be regarded in a technological context as a water collecting system. Photograph, Rachel Armstrong, July 2013.

The field of natural computing is inspired by the capabilities of natural organisms and embraces broad, overlapping and multidisciplinary practices such as digital modelling of biological systems and unconventional computing, as well as some aspects of robotics. ${ }^{15}$ The main goal is to develop programmable, lifelike systems using a spectrum of platforms to better understand and reflect the properties of living things, such as adaptation, learning, evolution, growth, development and robustness. Natural computing informs the technological character of vibrant matter and therefore guides the process of assemblage production that underpins ELT. However, as is the case with living technology, the term natural computing is very broad and relatively recently established, so its application has been developed and interpreted according to the aims of the various participating research groups. Research practices include the study of biomimicry in digital computing that notionally engages with material processes, mainly through representations in 'genetic algorithms'. However, my work relates to the direct manipulation of the chemical agency of matter to produce events which can be orchestrated by computational processes. With this focus in mind, two separately evolving yet overlapping practices that are grouped within the field of natural computing are of particular interest, namely, unconventional and morphological computing, which examine the direct impacts of material processes on computational tasks and may therefore assist in developing the technological potential of vibrant matter so that it can be applied within architectural design contexts.

15 Notably, the field of soft robotics is concerned with the computational properties of materials (Whitesides Research Group, 2011). 


\subsubsection{Unconventional Computing}

Unconventional computation has been defined from a range of perspectives, including technical, logical, scientific-theoretical and philosophical (MacLennan, 2011; Paun, 2005). According to Mihai Oltean, unconventional computers 'have been only recently invented, operate with some exotic principles, and ... have not been yet introduced on the market' (Oltean, 2009). Andrew Adamatzsky's research group at the University of South West England has built unconventional computing into a unique interdisciplinary research area and practice of analogue computing, which is concerned with the applications of biological and chemical systems to solve a range of challenges. For example, slime mould computing (see Fig. 2.15) has been used to identify the shortest route in compound pathways (Adamatzky et al, 2013), and dynamic chemistries can process complex information (Adamatzky, Costello and Ratcliffe, 2002; Adamatzky and De Lacy Costello, 2003). Adamatzky's aim is to enrich, or go beyond, the standard models of computing such as the Turing machine and von Neumann architectures, which have dominated computer science for more than half a century (Adamatzky et al, 2007; Armstrong, 2011b).

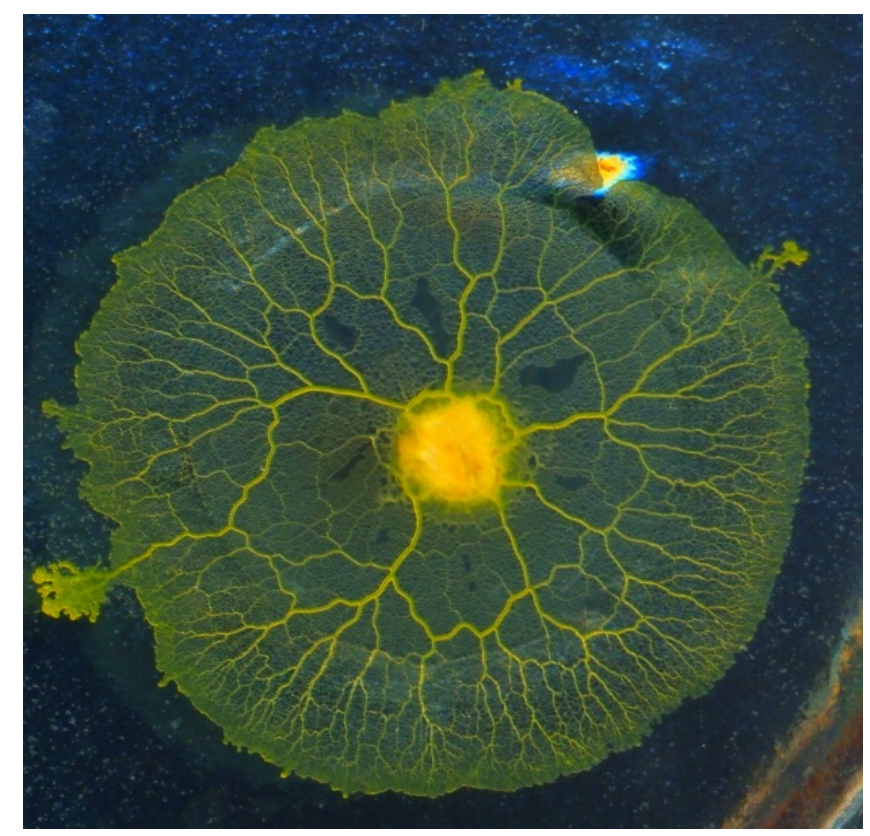

Figure 2.15: Slime mould Physarum polycephalum is a network of biochemical oscillators (Matsumoto et al, 1988) that can solve challenges such as, identifying transport routes within models of cities (Adamatzky et al, 2012). Photograph, courtesy Andrew Adamatzky, July 2013. 


\subsubsection{Morphological Computing}

Morphological computing incorporates the properties of matter to program the behaviour of a system. The term originated from the field of robotics, where the physical properties of robot bodies are harnessed to spontaneously produce and control the robot. Robots may exist as kinetic devices that act synergistically with the system's mechanics to automate it (Theo Jansen's Strandbeest, not dated), or may use entirely chemical approaches, such as Shingo Maeda's chemical inchworm (Gyr, 2009), which responds physically to changes in its environment. The idea is that the physical properties and morphology of agents such as living organisms, complex chemistries or machines constrain robotic interactions with the environment and therefore play a role in their development, growth and reconfiguration (Pfeifer and Iida, 2005) (see Fig. 2.16). Helmut Hauser observes that morphological computing is a way of outsourcing some of the computing processes performed by a central digital processing system to the physical body.

This is achieved by using non-classical engineering principles that embrace the qualities of high dimensionality, non-linearity, compliance and noise (Hauser, 2013). Technological assemblages may be regarded as morphological computers whose control systems are distributed throughout the operational body rather than being centralized. Morphological computing therefore needs soft control strategies,

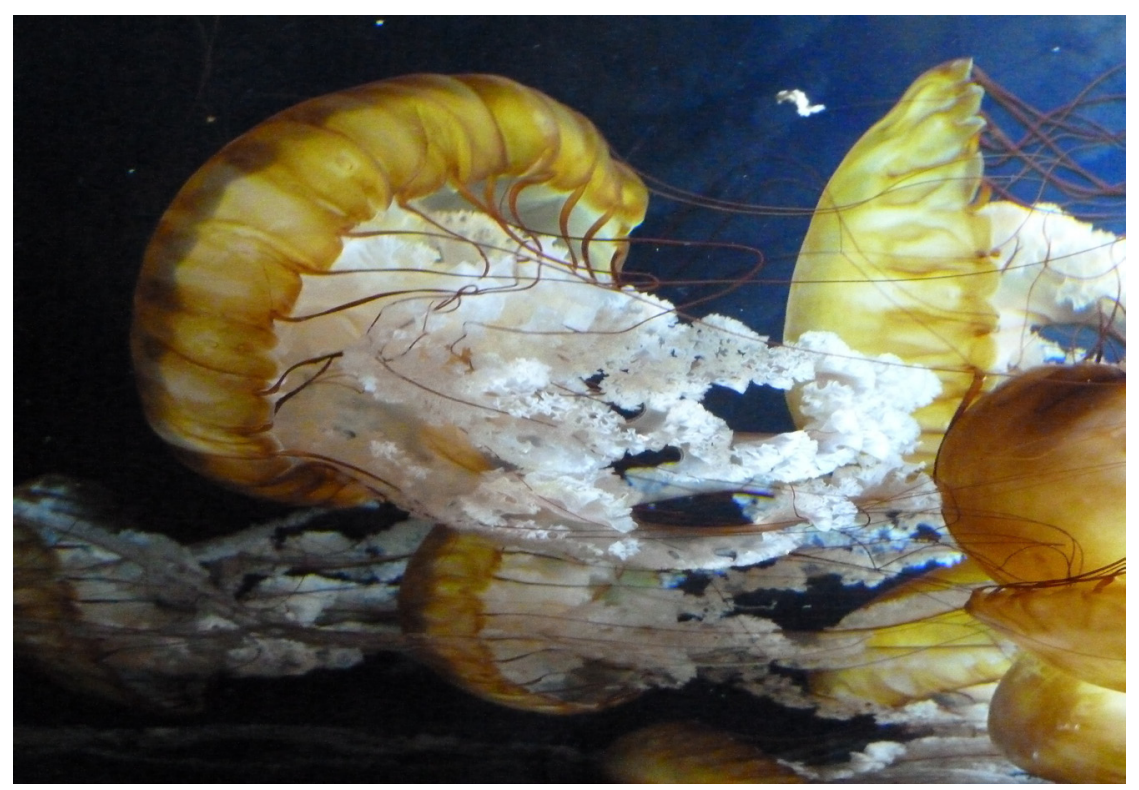

Figure 2.16: Jellyfish are able to swim without central control over this movement by virtue of the physical properties of their gel matrix.Photographs and collage, Rachel Armstrong, February 2011. 
which require orchestration rather than hierarchical command, and are already used in practices such as gardening and cooking. Additionally, control methods are coupled to the natural computing body and are able to respond variably to a range of different conditions within definable limits of probability. For example, the nervous and musculoskeletal system in the body have different levels and scales of control that are tightly coupled and variably engaged, depending on the sets of tasks they are required to address - from interactions at the cellular level to reflex movements and 'higher' centralized motor control. Varied outcomes exist within a possible set of circumstances, which are context sensitive and constrained by the physics and chemistry of the system. Morphological computing refers to a very specific research interest in the computational powers of dynamic chemistries (Armstrong and Hancyzc, 2013; Tangen and McCaskill, 2004-2008; Simonite, 2009) and material assemblages (Chu, 2012), which are regarded as 'soft robots' (Whitesides Research Group, 2011). The fundamental design units of morphological computing are not objects but leaky systems which spontaneously form as chemical and biological assemblages. These groupings enable information flow (droplets, proteins, DNA) and, ideally, can remain open (e.g. cells) throughout the computational process to transform substrates, rather than consume them. Morphological computing is not exclusively concerned with empirical outcomes but incorporates aesthetics and poetics in its outputs, such as quality of movement, colour changes, or by invoking 'the uncanny' (Freud, 2003).

\subsection{Vibrant Matter}

The term 'vibrant matter' is used to refer to different kinds of chemical assemblages that underpin the technological capabilities of the natural world. These enable Millennial Nature to spontaneously produce effects, or codesign events in collaboration with humans. The term was coined by Bennett as a philosophical and political project to 'to encourage more intelligent and sustainable engagements with vibrant matter and lively things' (Bennett, 2010, p.viii). As such, vibrant matter itself is a theoretical position that has not previously been applied to design practice. Additionally, I have used the term in reference to a model system that simultaneously incorporates materiality, infrastructure and technology as an experimental production platform that may be shaped by morphological computing approaches. Vibrant matter was selected to represent the cultural proposals implicit in my research, which aims to explore how 'deep' material imperatives, or 'sub-natures' (Gissen, 2011) may be harnessed in ways that demonstrate how inanimate materials 'exceed their status as objects and ... manifest traces of independence or aliveness, constituting the outside our own experience' (Bennett, 2010, p.xvi). Vibrant matter therefore refers the agency 
within and the substance of all material expressions - whether human or non-human, animate or inanimate.

Dynamic chemistries - ones that are far from equilibrium, or not at the lowest possible energy state in their context - are used to represent the design potential of vibrant matter. Far from equilibrium chemistries have been of scientific interest since the mid-19th century as a way of interrogating vitalism - the idea that matter is animated through the infusion of an ephemeral force. My research applies the uniquely lively properties of these agents to develop general design principles that may be applied more widely within architectural practice and include:

- Bütschli droplets: These agents spontaneously form when concentrated alkali solution is added to an olive oil field and exhibit strikingly lifelike qualities.

- Traube cells: These 'artificial plant cells' are produced when a blue crystal of copper II sulphate is dropped into a weak solution of potassium salt to create a seaweed-like, semi-permeable, inorganic membrane.

- Liesegang rings: These periodic patterns are produced when two interacting salt solutions produce weakly soluble precipitates.

- Leduc cells: These are produced when a crystal of calcium chloride is added to a dilute solution of sodium hydrogen carbonate forming a thin calcium carbonate shell.

By working at a level of design that precedes the emergence of systems that are culturally recognized as Nature, I seek to minimize the unconscious, cultural aestheticisms that complicate our observations, applications and expectations of the material world (Morton, 2007). My research attempts to affirm that inorganic substances may exert effects that are meaningful at the human scale in a design context, with characteristics (Bennett, 2011) that are not merely metaphorical relationships but could be explained through physical and chemical interactions - slowness, porosity and inorganic sympathy.

\subsubsection{Slowness}

The comparative endurance and patience of the non-human world exhibits a relative slowness in terms of its rate of change and may be explained by molecular dynamics. 


\subsubsection{Porosity}

The entangled and cooperating nature of bodies operates according to the laws of physics and chemistry in ways that make them susceptible to invasion or infusion with other bodies.

\subsubsection{Inorganic Sympathy}

Vibrant matter is driven towards a primaeval inorganic state of existence, which resonates with Erwin Schrödinger's notion of entropy and matter's decay towards equilibrium states (Schrödinger, 1944).

\subsection{Vibrant Architecture}

'Vibrant architecture' is a stochastic form of architecture that is compatible with a Nature-based method of architectural production. It seeks integration with living systems and emerges where vibrant matter converges with dynamic spatial programs, using ELT and morphological computing techniques. Vibrant architecture distinguishes itself from improved industrial practices such as Neri Oxman's view of 'material ecology' that uses parametrics to integrate material science and digital manufacturing with the environment (Oxman, 2012). It is also distinct from William McDonough and Michael Braungart's 'Cradle to Cradle' naturalistic urbanism (McDonough and Braungart, 2002), where buildings are considered 'alive' owing to the abundance of natural systems in the urban environment. Indeed, vibrant architecture is not 'inspired' by the natural world, like the practice of biomimicry (Beynus, 1997; Armstrong, 2013f), but directly embodies its material processes as an integral aspect of Millennial Nature (see Fig. 2.17).

\subsection{Summary}

This chapter establishes a portfolio of terms and contexts against which my research into a 21st century ecological design practice may be read and understood. 


\section{2 - Definitions}

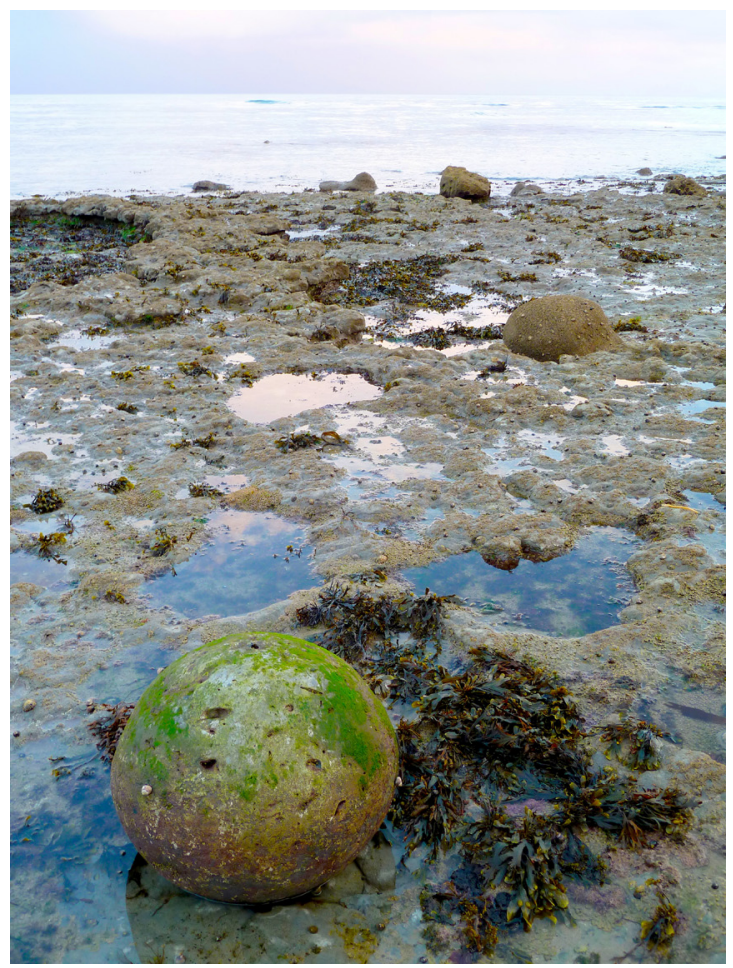

Figure 2.17: Stone structure at Lyme Regis forged by morphological computation. Photograph, Rachel Armstrong, July 2012. 